\title{
Association of serum monomeric periostin level with outcomes of acute exacerbation of idiopathic pulmonary fibrosis and fibrosing nonspecific interstitial pneumonia
}

\author{
Hiroshige Shimizu ${ }^{1}$, Susumu Sakamoto ${ }^{1}$, Masaki Okamoto ${ }^{2}$, Takuma Isshiki ${ }^{1}$, Junya Ono ${ }^{3}$, \\ Shigeki Shimizu ${ }^{4}$, Tomoaki Hoshino ${ }^{2}$, Kenji Izuhara ${ }^{5}$, Sakae Homma ${ }^{1,6}$
}

${ }^{1}$ Department of Respiratory Medicine, Toho University Omori Medical Center, Tokyo, Japan; ${ }^{2}$ Division of Respirology, Neurology, and Rheumatology, Department of Internal Medicine, Kurume University School of Medicine, Fukuoka, Japan; ${ }^{3}$ Shino-Test Corporation, Sagamihara, Japan; ${ }^{4}$ Department of Pathology, Kindai University Faculty of Medicine, Osaka-Sayama, Japan; ${ }^{5}$ Division of Medical Biochemistry, Department of Biomolecular Sciences, Saga Medical School, Saga, Japan; ${ }^{6}$ Department of Advanced and Integrated Interstitial Lung Diseases Research, School of Medicine, Toho University, Tokyo, Japan

Contributions: (I) Conception and design: H Shimizu, S Sakamoto, S Homma; (II) Administrative support: S Sakamoto; (III) Provision of study materials or patients: S Sakamoto, H Shimizu, T Isshiki, M Okamoto, T Hoshino, S Homma; (IV) Collection and assembly of data: H Shimizu, S Sakamoto, T Isshiki, M Okamoto, T Hoshino, S Homma; (V) Data analysis and interpretation: H Shimizu, S Sakamoto, M Okamoto, S Shimizu, K Izuhara; (VI) Manuscript writing: All authors; (VII) Final approval of manuscript: All authors.

Correspondence to: Susumu Sakamoto, MD. Department of Respiratory Medicine, Toho University Omori Medical Center, 6-11-1 Omori-nishi, Ota-ku, 143-8541, Tokyo, Japan. Email: susumu1029@gmail.com.

Background: The associations of serum monomeric periostin (M-PN) level and serial change in M-PN with acute exacerbation of chronic fibrosing interstitial pneumonia (AE-FIP) are unclear.

Methods: We prospectively measured serum M-PN level from onset of AE to day 14 in 37 patients with AE-FIP and evaluated its association with outcome. To determine localization of periostin expression, immunohistochemical staining of pathological lung tissue from autopsy cases of AE-IPF was evaluated.

Results: Data from 37 AE-FIP patients (28 men; age 73.9 7.8 years) were analyzed. With healthy controls as reference, serum M-PN level was significantly higher in patients with AE-FIP $(\mathrm{P}=0.02)$ but not in those with stable idiopathic pulmonary fibrosis $(\mathrm{P}=1.00)$. M-PN was significantly lower on day 7 than at AE-FIP onset in survivors $[14.6 \pm 5.8$ vs. $9.3 \pm 2.8 \mathrm{ng} / \mathrm{mL}$ (onset to day $7: \mathrm{P}<0.001$ )] but not in non-survivors [14.6 \pm 5.1 vs. $13.2 \pm 5.1 \mathrm{ng} / \mathrm{mL}$ (onset to day $7: \mathrm{P}=0.07$ )]. In analysis using a cut-off value for serial change in $\mathrm{M}-\mathrm{PN}$ $(\Delta M-P N), 3$-month survival was $92.3 \%$ in the $\Delta M-P N$ decrease group and $36 \%$ in the $\Delta M-P N$ increase group $(\mathrm{P}=0.002)$. In multivariate analysis, 3 -month survival tended to be associated with high $\triangle M-P N(O R$ : 12.4, 95\% CI: 0.82-187.9, P=0.069).

Conclusions: Serial change in serum M-PN level may be a prognostic indicator of AE-FIP.

Keywords: Acute exacerbation; fibrosing interstitial pneumonia; monomeric periostin

Submitted Jan 28, 2021. Accepted for publication Mar 21, 2021.

doi: $10.21037 / \mathrm{atm}-21-414$

View this article at: http://dx.doi.org/10.21037/atm-21-414

\section{Introduction}

Idiopathic pulmonary fibrosis (IPF) is a progressive disease in which growth of fibroblasts and excessive deposition of extracellular matrix (ECM) proteins result in abnormal lung structure and function $(1,2)$. The effects of transforming growth factor- $\beta$ (TGF- $\beta$ ) are an important mechanism of action; however, pathways involving molecules other than TGF- $\beta$ likely have roles in the growth of fibrotic tissues. Periostin is produced by the Th2-type cytokines interleukin-4 (IL-4) and interleukin-13 (IL-13) and has a 
key role in fibrosis, independent of TGF- $\beta$ (3-6). Periostin was expressed in lungs of mice with bleomycin-induced lung injury and in those of IPF patients (7-9).

Periostin has the characteristics of a matricellular protein-it promotes epithelial-mesenchymal transition (EMT) and regulation of activating fibroblasts/ myofibroblasts after binding $\alpha v \beta 3$ and $\alpha v \beta 5$ integrin-and functions as an ECM protein (2,7-9). Immunohistochemical staining of a lung biopsy specimen from a patient with stable IPF exhibited staining for periostin in fibroblastic foci only; staining was not observed in all fibrotic lung tissue (3). Additionally, serum periostin level was positively correlated with a temporal decrease in vital capacity $(\Delta \mathrm{VC})$ and diffusing capacity of the lung for carbon monoxide ( $\triangle$ DLCO) over a 6 -month period, and periostin might predict long-term outcomes for IPF (10). Periostin is present in respiratory epithelium of patients with bronchial asthma and during myocardial remodeling after myocardial infarction and progression of malignant tumors (2,11-13). As compared with traditional serum total periostin (T$\mathrm{PN}, \mathrm{SS} 18 \mathrm{~A} \times \mathrm{SS} 17 \mathrm{~B})$, serum monomeric periostin (M$\mathrm{PN}, \mathrm{SS} 20 \mathrm{~A} \times \mathrm{SS} 19 \mathrm{D})$, which specifically reflects fibrosis in interstitial pneumonias (IIPs), is more useful for evaluating disease activity in chronic fibrosing interstitial pneumonia (FIP) (14). Ohta et al. (14) reported that, in IPF patients, serum M-PN level was more strongly correlated than either Krebs von den Lungen-6 (KL-6) or surfactant protein-D (SP-D) levels with change in \%VC and \% DLCO during a 6-month period. This suggests that M-PN level could be used to predict outcomes for IPF patients. The natural history of IPF is heterogeneous and may include periods of acute respiratory deterioration, which are termed acute exacerbations of IPF (AE-IPF) when a cause cannot be identified $(15,16)$. The prognosis of AE-IPF is very poor (15-17). The time course of serum M-PN level and its role in acute exacerbation of FIP (AE-FIP) have not been extensively described. Serum fibrotic maker such as KL-6 or SP-D are usually more elevated in AE-FIP than in the stable phase, and fibrosis of the lung parenchyma sometimes rapidly progresses after AE-FIP. Thus, we hypothesized that serum M-PN level would be elevated in patients with AE-FIP and might be associated with AE-FIP outcomes. The purpose of this study was to evaluate serum M-PN level and its association with outcome in patients with AEFIP. We present the following article in accordance with the STROBE reporting checklist (available at http://dx.doi. org/10.21037/atm-21-414).

\section{Methods}

\section{Subjects}

We prospectively measured serum M-PN levels in 37 patients with AE-FIP who were admitted to our hospital during the period from January 2013 through March 2017. We assessed change in serum M-PN level from onset of AE-FIP to day 14 (days 0, 7, and 14) by using an enzymelinked immunosorbent assay (ELISA) for M-PN that included monoclonal antibodies to M-PN, as previously described (a new periostin ELISA Kit, SHINO-TEST Corporation, Kanagawa, Japan) (14). Serum M-PN level was also measured in patients with stable IPF $(n=11)$ and in healthy controls $(n=5)$. These results were compared to those for patients with AE-FIP. On the basis of 3-month outcomes, the patients were classified as survivors $(n=21)$ and non-survivors $(\mathrm{n}=16)$. Patient background, clinical characteristics, and serum M-PN level were compared between these two groups, as was serial change in serum M-PN. Finally, using univariate and multivariate analysis, we identified factors contributing to 3 -month survival.

\section{Diagnosis of FIP}

Diagnosis of FIP was based on the 2013 update of the international multidisciplinary classification of the idiopathic interstitial pneumonias (15) and $2018 \mathrm{IPF}$ guidelines of the American Thoracic Society (ATS)/ European Respiratory Society (ERS)/Japanese Respiratory Society (JRS)/Latin-American Thoracic Association (ALAT) (18). In this study, FIP comprises IPF and nonspecific interstitial pneumonia (NSIP). IPF was diagnosed on the basis of usual interstitial pneumonia (UIP) or probable UIP patterns on high-resolution computed tomography (HRCT) images. Diagnosis of NSIP was based on histopathogical patterns or HRCT patterns showing the presence of traction bronchiectasis with a peribronchovascular distribution and/or intralobular reticular opacity and, less frequently, peripheral distribution and/or a wide extent of ground-glass attenuation. All diagnoses of interstitial pneumonia were confirmed by multidisciplinary discussion. We assessed FIP severity before $\mathrm{AE}$ onset by using the interstitial lung diseases-gender, age, and physiology (ILD-GAP) model 
proposed by Ryerson et al. (16), and JRS criteria.

\section{Diagnosis of AE-FIP}

Diagnosis of AE was based on criteria reported by Collard et al. $(17,18)$. Chest CT images were scored according to a report by Kazerooni et al. (19) and included fibrosis score and ground-glass score. Furthermore, using the classification of Akira et al. (20), we classified CT pattern at AE-FIP onset as diffuse, peripheral, or multifocal.

\section{Treatment of AE-FIP}

All patients were treated with high-dose corticosteroid pulse therapy (methylprednisolone $1,000 \mathrm{mg}$ /day for 3 days). Corticosteroid dose was tapered after pulse therapy $(0.5-1.0 \mathrm{mg} / \mathrm{kg} / \mathrm{day})$ in all patients. Cotrimoxazole (a combination antibiotic containing trimethoprim and sulfamethoxazole) was prescribed for prevention of pneumocystis pneumonia. Cyclosporine A $(2.5 \mathrm{mg} / \mathrm{kg} / \mathrm{day})$ and $/$ or recombinant human thrombomodulin $(0.06 \mathrm{mg} / \mathrm{kg} /$ day $)$ therapy were administered for severe disease (lower $\mathrm{PaO}_{2} /$ $\mathrm{FiO}_{2}$ ratio and/or a diffuse HRCT pattern).

\section{Immunobistochemical assay}

We retrospectively selected 5 lung tissue samples obtained from consecutive patients with AE-IPF (5 men; median age, 67 years) who had undergone autopsy after death from AE during the period from January 2007 through December 2017 in a collaborating research facility. Additionally, we randomly selected 5 samples of lung tissue obtained from patients with stable IPF (5 men; median age, 66 years) who had undergone surgical lung biopsy (SLB) during the above period. These samples were fixed with $10 \%$ formalin and embedded in paraffin wax for conventional hematoxylin and eosin staining. Immunohistochemical analysis was performed as reported previously (3). Briefly, rat anti-human periostin monoclonal antibodies (mAbs) of immunoglobulin

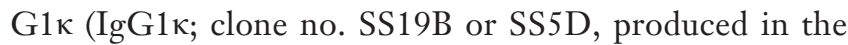
lab of Biomolecular Sciences, Saga Medical School, Saga, Japan) were diluted to $1: 1,000$ and applied to the sections, which were then stored overnight at $4^{\circ} \mathrm{C}$. Positive reactivity was identified with the EnVision ${ }^{\mathrm{TM}}+$ Dual Link SystemHRP (DAKO, Japan). Mouse anti-human alpha-smooth muscle actin ( $\alpha$-SMA)-Abs (clone 1A4, Dako, Japan) were

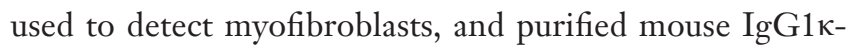
Abs (BioLegend, USA) were used as negative controls.

\section{Statistical analysis}

The Wilcoxon rank sum test and chi-square test were used to compare two groups. The Kruskal-Wallis test was used for comparisons among 3 groups.

Correlations between two variables were evaluated by using Spearman's rank correlation coefficients. Cox proportional hazards regression was used to analyze prognostic factors. Receiver operating characteristic (ROC) curves were used to determine the optimal cutoff value for serum M-PN at onset in prognostic factor analysis. Kaplan-Meier analysis was used to investigate survival rate, and significant differences were analyzed with the logrank test. Results are expressed as mean $\pm \mathrm{SD}$, and the level of statistical significance was set at $\mathrm{P}<0.05$. The software package SPSS version 11.0 (SPSS Inc., Chicago, IL, USA) was used for all statistical analysis.

\section{Ethics}

The study was conducted in accordance with the Declaration of Helsinki (as revised in 2013). This study was approved by the Institutional Review Board of Toho University Omori Medical Center (project approval no.: 27-129; approval date: September 17, 2015). All patients or their families provided written informed consent, and medical records were reviewed with the approval of the Institutional Review Board.

\section{Results}

Serum M-PN levels in patients with AE-FIP, patients with stable IPF, and bealthy controls

Serum M-PN level was $14.5 \pm 5.4 \mathrm{ng} / \mathrm{mL}$ in patients with AEFIP $(n=37), 14.0 \pm 6.3 \mathrm{ng} / \mathrm{mL}$ in patients with stable IPF $(n=11)$, and $8.3 \pm 2.2 \mathrm{ng} / \mathrm{mL}$ in healthy controls $(\mathrm{n}=5)$. Serum M-PN level was significantly higher in patients with AE-FIP than in healthy participants $(\mathrm{P}=0.02)$ but did not differ between patients with stable IPF and those with AE-FIP $(\mathrm{P}=1.00)$. However, M-PN level was not significantly higher in stable IPF patients than in healthy control $(\mathrm{P}=0.07)$ (Figure 1).

\section{Clinical characteristics of survivors and non-survivors}

Table 1 shows the clinical characteristics of survivors and nonsurvivors at $\mathrm{AE}$ onset and before $\mathrm{AE}$. The cause of death for all non-survivors was respiratory failure due to AE-FIP. There was no significant difference between the groups in 


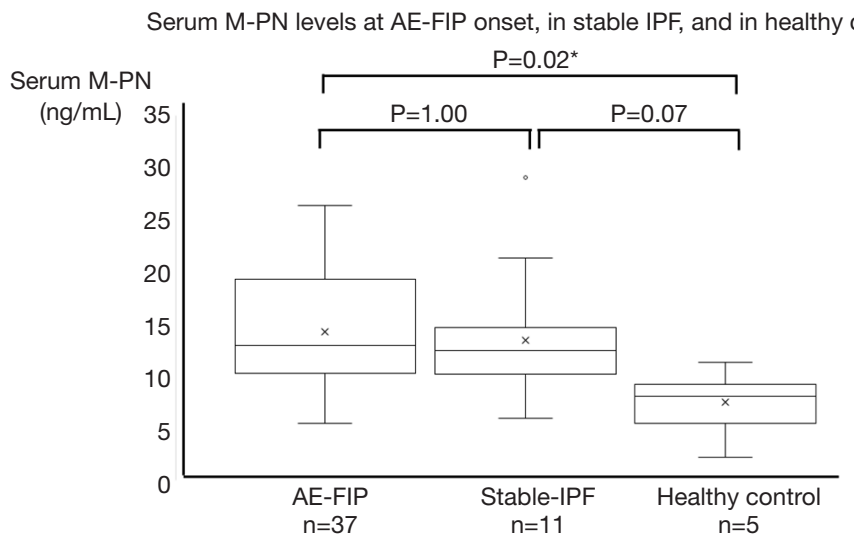

Figure 1 Serum monomeric periostin (M-PN) levels in patients with AE-FIP, patients with stable IPF, and healthy controls. The whiskers show ranges, and the bars indicate mean M-PN levels. Serum M-PN level was significantly higher in AE-FIP patients than in healthy controls. ${ }^{*} \mathrm{P}<0.05$.

Table 1 Clinical characteristics of survivors and non-survivors

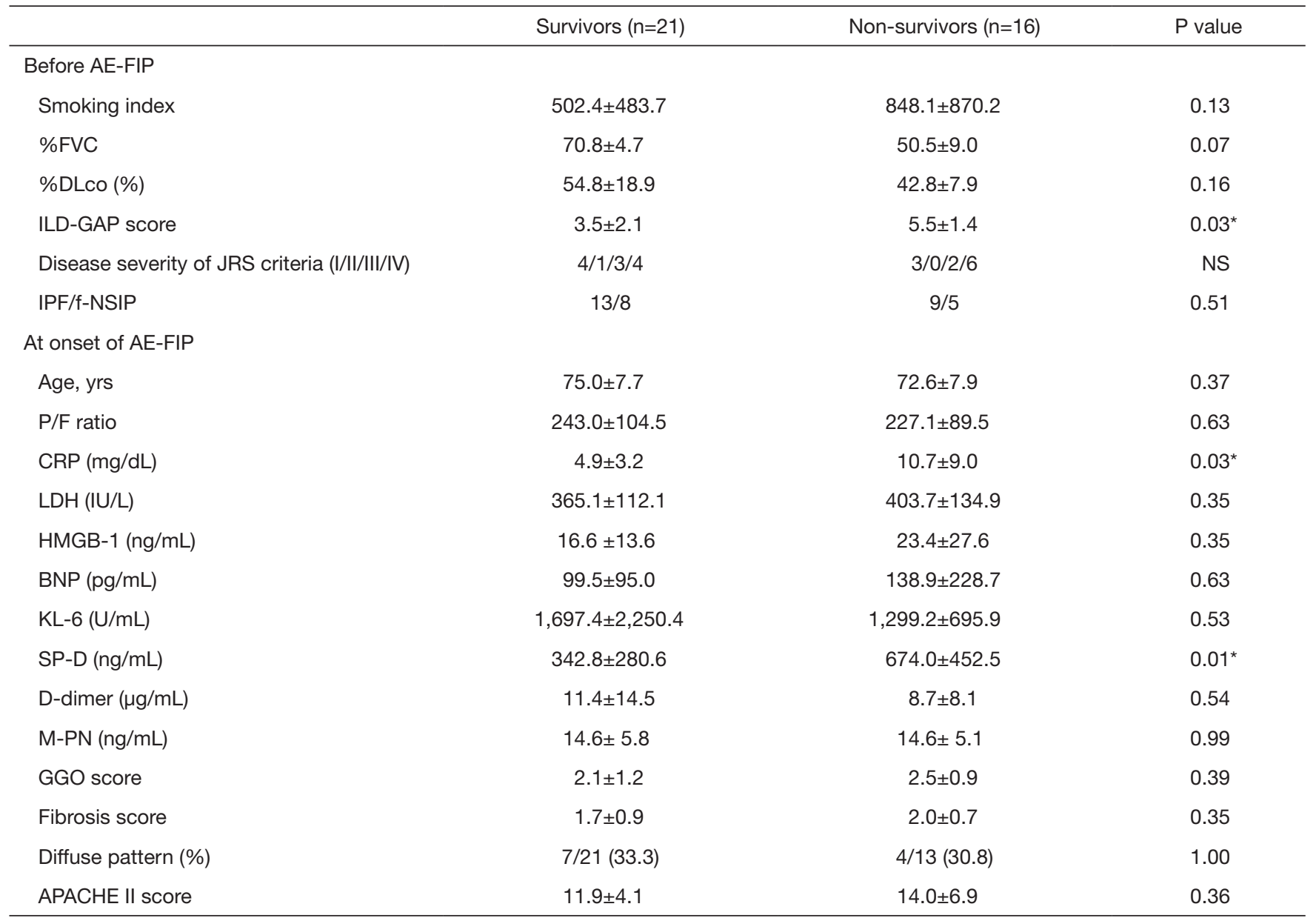

${ }^{*} \mathrm{P} \leq 0.05$. \%FVC, \%forced vital capacity; \%DLco, diffusing capacity for carbon monoxide; ILD-GAP; $\mathrm{P} / \mathrm{F}$ ratio, $\mathrm{PaO} / \mathrm{FiO}{ }_{2}$ ratio; $\mathrm{CRP}$, C-reactive protein; LDH, lactate dehydrogenase; HMGB-1, high mobility group box-1; BNP, brain natriuretic peptide; SP-D, surfactant protein-D; M-PN, monomeric periostin. 
Table 2 Serum periostin level at AE-FIP onset and its correlation with clinical characteristics

\begin{tabular}{|c|c|c|}
\hline & $\mathrm{R}$ & $P$ value \\
\hline \multicolumn{3}{|l|}{ Before AE-FIP } \\
\hline \%FVC (L) & -0.59 & $0.004^{*}$ \\
\hline \%DLco (\%) & -0.48 & $0.027^{*}$ \\
\hline ILD-GAP score & 0.40 & $0.04^{\star}$ \\
\hline \multicolumn{3}{|c|}{ At the onset of $A E-F I P$} \\
\hline WBC $\left(\times 10^{3} / \mu \mathrm{L}\right)$ & 0.15 & 0.36 \\
\hline CRP (mg/dL) & 0.04 & 0.84 \\
\hline HMGB-1 (ng/mL) & 0.18 & 0.32 \\
\hline LDH (IU/L) & -0.04 & 0.82 \\
\hline D-dimer $(\mu \mathrm{g} / \mathrm{mL})$ & 0.29 & 0.11 \\
\hline $\mathrm{P} / \mathrm{F}$ ratio & -0.18 & 0.28 \\
\hline $\mathrm{BNP}(\mathrm{pg} / \mathrm{mL})$ & 0.45 & $0.01^{*}$ \\
\hline $\mathrm{KL}-6(\mathrm{U} / \mathrm{mL})$ & -0.02 & 0.90 \\
\hline SP-D (ng/mL) & -0.10 & 0.57 \\
\hline SP-A (ng/mL) & -0.18 & 0.33 \\
\hline UIP pattern & 0.41 & $0.01^{*}$ \\
\hline GGO score & -0.12 & 0.52 \\
\hline Fibrosis score & 0.44 & $0.01^{*}$ \\
\hline Diffuse pattern & 0.06 & 0.74 \\
\hline APACHE II score & 0.03 & 0.87 \\
\hline
\end{tabular}

${ }^{*} \mathrm{P} \leq 0.05$. \%FVC, \%forced vital capacity; \%DLco, diffusing capacity for carbon monoxide; ILD-GAP; P/F ratio, $\mathrm{PaO}_{2} / \mathrm{FiO}_{2}$ ratio; $\mathrm{CRP}, \mathrm{C}$-reactive protein; $\mathrm{LDH}$, lactate dehydrogenase; HMGB-1, high mobility group box-1; BNP, brain natriuretic peptide; SP-D, surfactant protein-D; M-PN, monomeric periostin.

age, $\mathrm{PAO}_{2} / \mathrm{FIO}_{2}(\mathrm{P} / \mathrm{F})$ ratio, serum lactate dehydrogenase (LDH) level, brain natriuretic peptide (BNP) level, KL-6 level, D-dimer level, or ground-glass opacity (GGO) score or fibrosis score on HRCT. However, ILD-GAP score before $\mathrm{AE}$ onset was significantly lower in survivors than in non-survivors $(3.5 \pm 2.0$ vs. $5.5 \pm 1.4, \mathrm{P}=0.03)$. In addition, serum C-reactive protein (CRP) level and SP-D level at AEFIP onset were significantly lower in survivors than in nonsurvivors $(4.9 \pm 3.2$ vs. $10.7 \pm 9.0, \mathrm{P}=0.01$, and $342.8 \pm 280.6$ vs. $674.0 \pm 452.5, \mathrm{P}=0.01$, respectively). Duration of survival was significantly longer in survivors than in non-survivors (457.0 \pm 478.0 vs. $27.8 \pm 29.0$ days, $\mathrm{P}=0.001$ ).

\section{Serum periostin level at AE-FIP onset and its correlation with clinical characteristics}

Serum M-PN level at AE onset was weakly correlated with definite UIP pattern, fibrosis score on HRCT, serum D-dimer level, BNP, latest pulmonary function test results, ILD-GAP score, \%FVC, and \%DLco (BNP: $R=0.45$, $\mathrm{P}=0.01$; UIP pattern: $\mathrm{R}=0.41, \mathrm{P}=0.01$; fibrosis score: $\mathrm{R}=0.44$, $\mathrm{P}=0.01$; ILD-GAP score: $\mathrm{R}=0.40, \mathrm{P}=0.04 ; \% \mathrm{FVC} ; \mathrm{R}=-0.59$, $\mathrm{P}=0.004 ; \% \mathrm{DLco} ; \mathrm{R}=-0.48, \mathrm{P}=0.027$ ).

Serum M-PN was not correlated with age, sex, P/ $\mathrm{F}$ ratio, white blood cell count, serum levels of CRP, LDH, KL-6, SP-D, SP-A, or high-mobility group box 1 protein (HMGB1), diffuse HRCT pattern, GGO score, or APACHE II score (Table 2).

\section{Change in serum M-PN levels in survivors and non-survivors}

Serum M-PN level at onset of AE did not significantly differ between survivors $(\mathrm{n}=21)$ and non-survivors $(\mathrm{n}=16)(14.6 \pm 5.8$ vs. $14.6 \pm 5.1 \mathrm{ng} / \mathrm{mL}$, respectively, $\mathrm{P}=0.91$ ) (Figure 2). Analysis of serial change in M-PN level from onset of AE-FIP to day 7 , and from day 0 to day 14 , showed that M-PN level significantly decreased in survivors $[14.6 \pm 5.8 v s .9 .3 \pm 2.8 \mathrm{ng} / \mathrm{mL}$ (onset to day $7 ; \mathrm{P}<0.001$ ), and $14.6 \pm 5.8$ vs. $9.8 \pm 3.9 \mathrm{ng} / \mathrm{mL}$ (onset to day $14 ; \mathrm{P}<0.001$ )]. However, there was no significant decrease in $\mathrm{M}-\mathrm{PN}$ level from $\mathrm{AE}$ onset to day 7 in nonsurvivors $[14.6 \pm 5.1$ vs. $13.2 \pm 5.1 \mathrm{ng} / \mathrm{mL}$ (onset to day 7 ; $\mathrm{P}=0.07)]$. There was a significant decrease in $\mathrm{M}-\mathrm{PN}$ from $\mathrm{AE}$ onset to day 14 in non-survivors [14.6 \pm 5.1 vs. $9.8 \pm 3.1 \mathrm{ng} / \mathrm{mL}$ (onset to day 14; $\mathrm{P}=0.03$ )] (Figure 2).

Using these data, we evaluated the association of change in M-PN level with 3-month survival. ROC curves were used to determine the optimal cutoff value of $\triangle \mathrm{M}-\mathrm{PN}$ (expressed as change in M-PN from day 0 to day 7) for predicting survival, which was $-2.7 \mathrm{ng} / \mathrm{mL}$ (sensitivity, $85.7 \%$; specificity, $75.0 \%$; area under the curve, 0.73) (Figure 3). The patients were then divided into a decrease group $(<-2.7 \mathrm{ng} / \mathrm{mL})$ and increase group $(\geq-2.7 \mathrm{ng} / \mathrm{mL})$. Survival at 3 months was significantly better in the decrease group $(92.3 \%)$ than in the increase group $(36.3 \%)(\mathrm{P}=0.002)$ (Figure 4).

\section{Factors predicting 3-month survival}

Univariate analysis of patients with AE-FIP identified the following factors as predictors of 3-month survival: a $\triangle \mathrm{M}-\mathrm{PN}$ of $\geq-2.7 \mathrm{ng} / \mathrm{mL}$ (OR: 18.0, 95\% CI: 1.63-198.5, $\mathrm{P}=0.012$ ), 


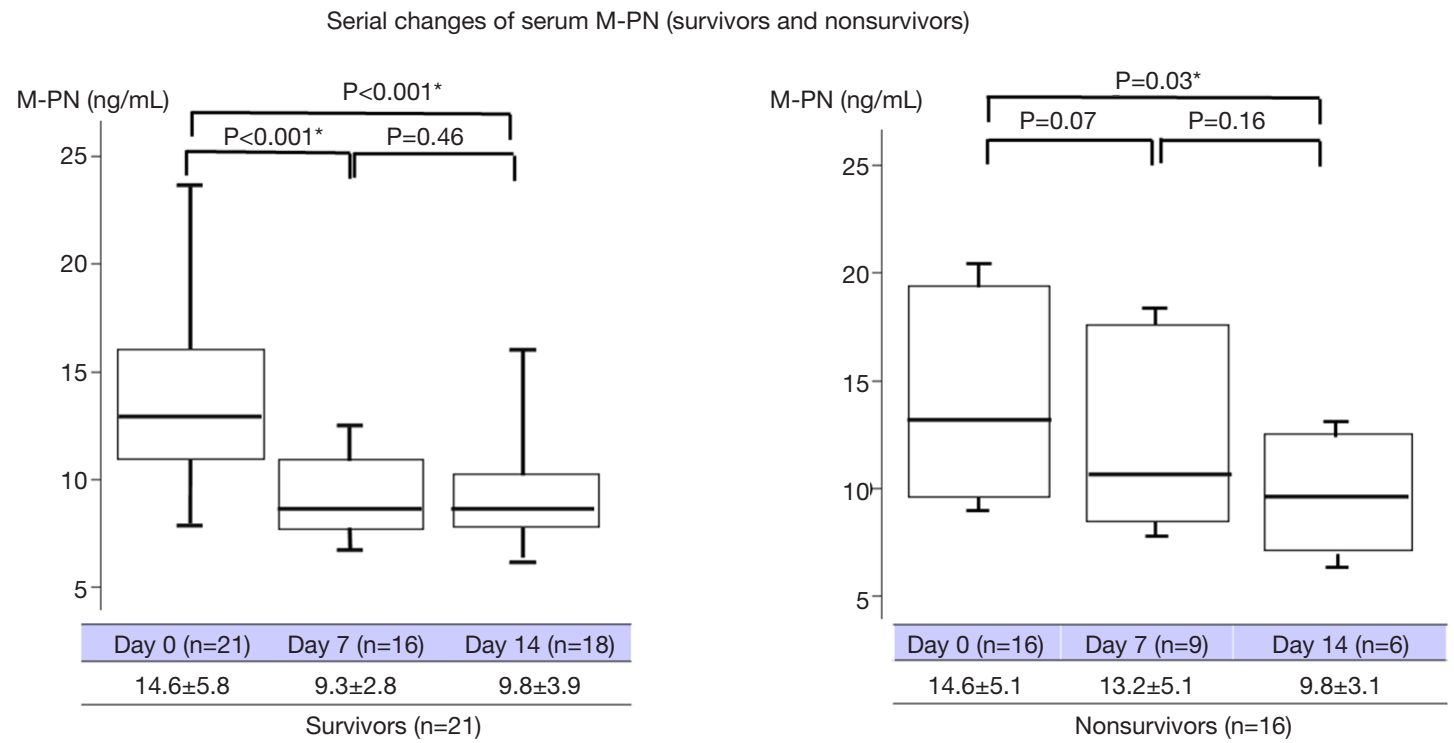

Figure 2 Change in serum M-PN level in survivors and non-survivors. The whiskers show ranges, the bars show median M-PN levels, and " $\mathrm{x}$ " indicates mean M-PN level. Among survivors, serum M-PN level was significantly lower on day 7 than on day 0 (9.3 $\pm 2.8 v s$. $14.6 \pm 5.8 \mathrm{ng} / \mathrm{mL}$, respectively; $\mathrm{P}<0.001)$. In contrast, serum $\mathrm{M}-\mathrm{PN}$ level did not significantly change in non-survivors $(14.6 \pm 5.1$ vs. $13.2 \pm 5.1 \mathrm{ng} / \mathrm{mL}$, respectively; $\mathrm{P}=0.07) .{ }^{*} \mathrm{P}<0.05$.

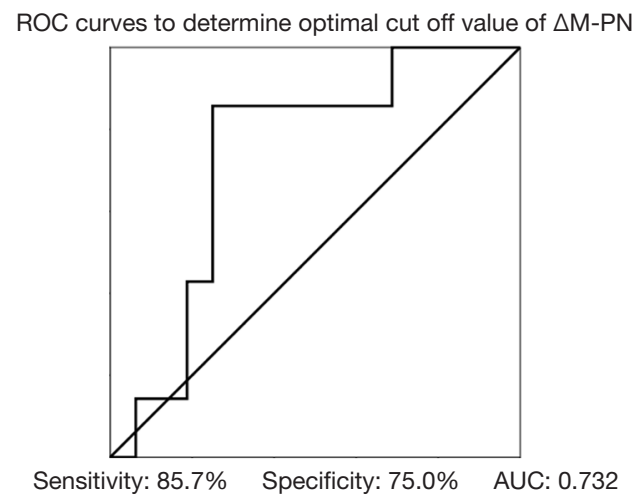

Figure 3 ROC curves to determine the optimal cutoff value of $\triangle \mathrm{M}-\mathrm{PN}$ (expressed as change in M-PN from day 0 to day 7 ) for predicting survival, which was $-2.7 \mathrm{ng} / \mathrm{mL}$ (sensitivity, $85.7 \%$; specificity, $75.0 \%$; area under the curve, 0.732 ).

SP-D (OR: 1.00, 95\% CI: 1.00-1.01, $\mathrm{P}=0.03$ ), and CRP at AE-FIP onset (OR: 1.18, 95\% CI: 1.02-1.36, $\mathrm{P}=0.03$ ).

Multivariate analysis was performed by using the forced entry method with a variable that was statistically significant in univariate analysis. Multivariate analysis showed that 3-month survival tended to be associated with high $\triangle M-P N$ (OR: 12.4, 95\% CI: 0.82-187.9, P=0.069) (Table 3).

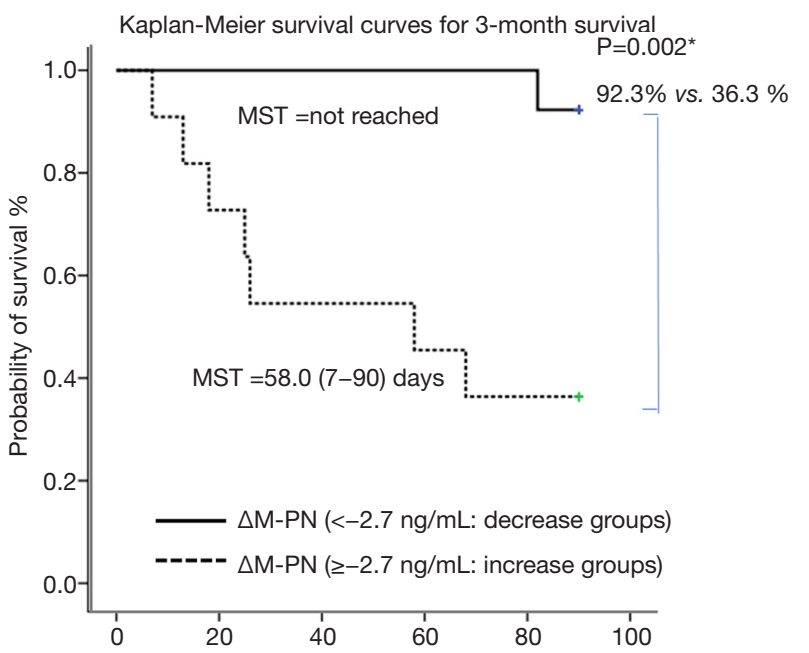

Figure 4 Kaplan-Meier survival curves for 3-month survival in patients with a $\Delta M-P N$ of $<-2.7 \mathrm{ng} / \mathrm{mL}(\mathrm{n}=13)$ and $>-2.7 \mathrm{ng} / \mathrm{mL}$ $(\mathrm{n}=11)$. Survival at 3 months was significantly better for a $\triangle M-P N$ of $<-2.7 \mathrm{ng} / \mathrm{mL}(\mathrm{n}=13)$ than for a $\Delta M-P N$ of $\geq-2.7 \mathrm{ng} / \mathrm{mL}(\mathrm{n}=11)$ (92.3\% vs. $36.3 \%$, respectively; $\mathrm{P}=0.002$ ). ${ }^{*} \mathrm{P}<0.05$.

\section{Localization of periostin in autopsied lung specimens with AE-IPF and SLB specimens with stable IPF}

We retrospectively analyzed lung tissue samples obtained by 
Table 3 Univariate and multivariate analysis of predictors of 3-month mortality

\begin{tabular}{|c|c|c|c|}
\hline & OR & $95 \% \mathrm{Cl}$ & $P$ value \\
\hline \multicolumn{4}{|l|}{ Before AE-FIP } \\
\hline \%FVC (L) & 0.94 & $0.88-1.01$ & 0.09 \\
\hline \%DLco (\%) & 0.93 & $0.86-1.01$ & 0.10 \\
\hline \multicolumn{4}{|l|}{ At the onset of AE-FIP } \\
\hline Age, yrs & 0.96 & $0.88-1.05$ & 0.37 \\
\hline $\mathrm{P} / \mathrm{F}$ ratio & 1.00 & $0.99-1.01$ & 0.62 \\
\hline $\mathrm{CRP}(\mathrm{mg} / \mathrm{dL})$ & 1.18 & $1.02-1.36$ & $0.03^{*}$ \\
\hline SP-D (ng/mL) & 1.00 & $1.00-1.01$ & $0.03^{*}$ \\
\hline D-dimer $(\mu \mathrm{g} / \mathrm{mL})$ & 0.98 & $0.92-1.04$ & 0.53 \\
\hline HMGB-1 (ng/mL) & 1.02 & $0.98-1.06$ & 0.35 \\
\hline Fibrosis score & 1.61 & $0.61-4.24$ & 0.34 \\
\hline GGO score & 1.38 & $0.67-2.85$ & 0.38 \\
\hline M-PN, day $0(\mathrm{ng} / \mathrm{mL})$ & 0.99 & $0.88-1.12$ & 0.91 \\
\hline Diffuse pattern & 0.89 & $0.20-3.93$ & 0.88 \\
\hline Serum $\Delta M-P N \geq-2.7(\mathrm{ng} / \mathrm{mL})$ & 12.4 & $0.82-187.9$ & 0.069 \\
\hline $\mathrm{CRP}(\mathrm{mg} / \mathrm{dL})$ & 1.27 & $0.90-1.80$ & 0.18 \\
\hline SP-D (ng/mL) & 1.00 & $1.00-1.01$ & 0.30 \\
\hline
\end{tabular}

${ }^{*} \mathrm{P} \leq 0.05$. \%FVC, \%forced vital capacity; \%DLco, diffusing capacity for carbon monoxide; ILD-GAP; $\mathrm{P} / \mathrm{F}$ ratio, $\mathrm{PaO} / \mathrm{FiO}_{2}$ ratio; $\mathrm{CRP}$, C-reactive protein; LDH, lactate dehydrogenase; HMGB-1, high mobility group box-1; BNP, brain natriuretic peptide; SP-D, surfactant protein-D; M-PN, monomeric periostin.

SLB from 5 patients with stable IPF and by autopsy from 5 patients with AE-IPF. Representative findings of SLB and autopsied specimens obtained from a 66-year-old man with IPF are shown in Figure 5. SLB specimens of stable IPF showed strong expression of periostin in fibroblastic foci, with patchy distributions, as previously reported (Figure $5 A$ ). Autopsied specimens obtained from patients with AE-IPF also showed strong expression in fibrotic lesions. Fibrotic lesions with periostin expression were larger in autopsied specimens than in SLB specimens (Figure 5B). Periostin was not expressed in alveolar or bronchiolar epithelial cells, or in alveolar mononuclear cells. Localization of periostin was moderately consistent with that of $\alpha$-SMApositive cells, namely myofibroblasts (Figure $5 A, B$ ). IgG1א was not expressed in fibroblastic foci or in alveolar or bronchiolar epithelial cells but was weakly stained in alveolar 
A

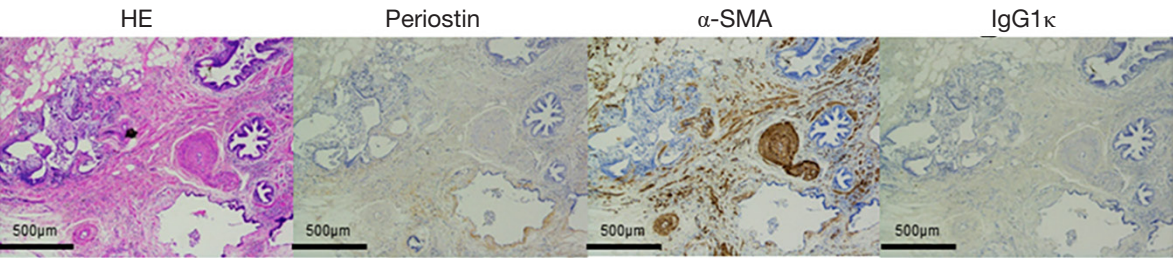

Stable IPF

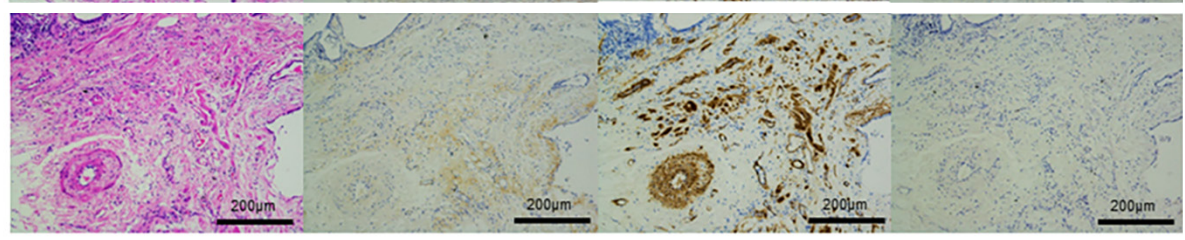

$\bar{B}$

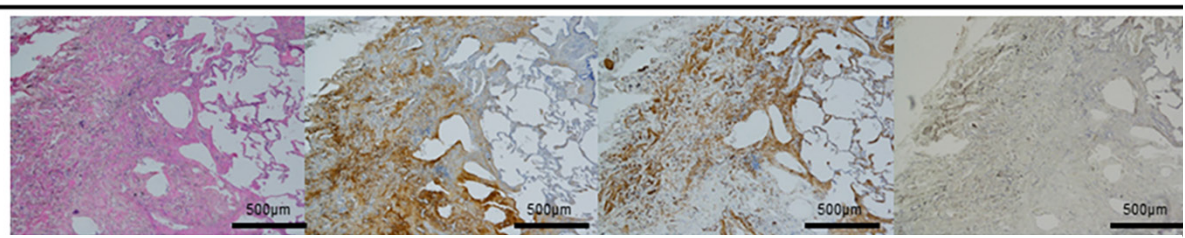

AE-IPF

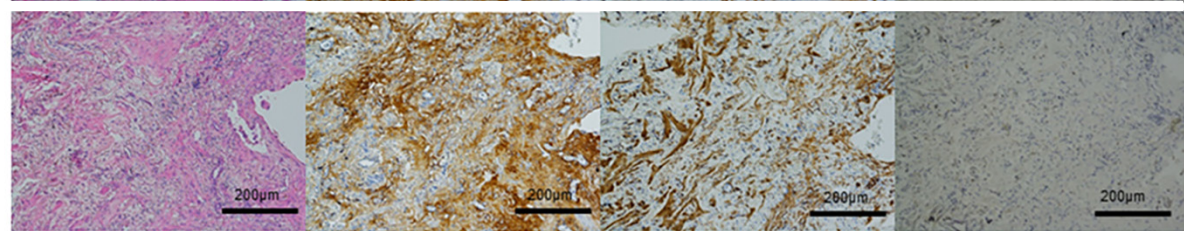

Figure 5 Representative findings of SLB and autopsied specimens obtained from a 66-year-old man with IPF. (A) Stable IPF. SLB specimens of stable IPF showed strong expression of periostin in fibroblastic foci, with patchy distributions. (B) AE-IPF. Autopsied specimens obtained from patients with AE-IPF also showed strong expression in fibrotic lesions. The numbers of periostin-positive cells and $\alpha$-SMA-positive cells in fibrotic lesions were higher in AE-IPF than in stable IPF. HE: hematoxylin and eosin staining; Periostin: rat anti-human periostin

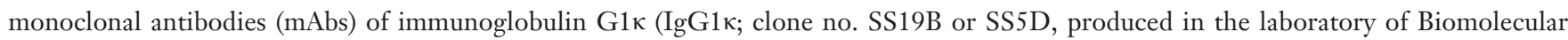
Sciences, Saga Medical School, Saga, Japan); $\alpha$-SMA: mouse anti-human alpha-smooth muscle actin ( $\alpha$-SMA)-Abs (clone 1A4, Dako, Japan);

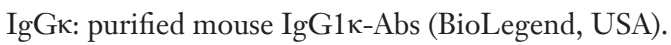

mononuclear cells (Figure $5 A, B$ ). Therefore, positive staining by anti-periostin-mAbs in fibrotic lesions of IPF does not appear to include nonspecific reactions via such as the Fcreceptor of immunoglobulin.

\section{Discussion}

$\mathrm{AE}$ of idiopathic interstitial pneumonias (IIPs) is a disease concept that originated in Japan (21) and is characterized by diffuse alveolar damage of unknown cause. The prognosis is poor (mortality rate, $50 \%$ to $80 \%$ ), and it accounts for $40 \%$ of deaths from IPF $(22,23)$. The causes include idiopathic, viral, and bacterial infection and aspiration (24-26). However, $\mathrm{AE}$ is not well understood. Recent molecular studies have focused on the involvement of immunomodulators such as annexin-1, heat shock protein 47 (HSP47), and ST2 proteins (27-29). CRP level during AE-IPF was higher in non-survivors than in survivors (22). In the present study, CRP was related to a predictor of 3-month survival. Although the pathogenesis of AE-IPF is known to be associated with inflammation, a specific biomarker of AE-FIP outcomes has not been identified.

Periostin is stained in early fibroblastic foci and was reported to be a long-term prognostic factor for IPF $(6,7,9,14,30)$. Fibroblastic foci in pathological specimens were nonsignificantly larger in patients with postoperative AE of interstitial pneumonia $(5,30,31)$. Serum periostin levels correlate with the amount of fibroblastic foci; thus, fibroblast activity may also be involved in AE of FIP. Recently, Ohta et al. (14) developed a new M-PN kit that is more specific than total periostin in diagnosing IPF.

In this study, we evaluated serum M-PN level at AE onset and serial change in M-PN level in patients with AE-FIP. In addition, we evaluated the correlation of serum M-PN with outcome. Although serum M-PN levels at the onset of 
AE-FIP did not differ in stable IPF, there was a significant difference with healthy controls. In this study, M-PN value was not useful for diagnosing AE-FIP. We did not analyze the difference in M-PN between FIP-stable and FIP-AE patients because patients without IPF were included in the sample. In a comparison of serum M-PN in patients with FIP-AE and stable IPF, serum M-PN was not significantly higher at the onset of AE than in stable IPF $(14.5 \pm 5.4 v s$. $14.0 \pm 6.3 \mathrm{ng} / \mathrm{mL}$, respectively, $\mathrm{P}=1.00)$. Furthermore, $M-\mathrm{PN}$ values at day 7 and day 14 in survivors and at day 14 in nonsurvivors did not statistically differ from the value for stable IPF. There are several potential explanations for this finding. First, serum periostin levels correlate with the extent of fibrosis in CT images in stable IPF, so M-PN values differ in relation to the spread of individual fibrosis (3). Therefore, to confirm how M-PN changes from the stable period to the period of exacerbation, it must be measured before and after the onset of AE-IPF in the same patients; however, we could not evaluate serum M-PN level before AE-FIP onset. Second, inclusion of f-NSIP $(n=14)$ in the FIP patients may have resulted in a lower M-PN level than in AE-IPF patients, as a previous study reported that M-PN values tended to be higher in stable IPF than in f-NSIP (14). Finally, eight of 37 patients died within 14 days in this study. The absence of data for these non-survivors, who likely would have had higher M-PN values, might explain our finding of a lower M-PN level at day 14.

During follow-up of AE-FIP patients, serum M-PN level decreased in most patients as their condition improved, which suggests that M-PN level is higher at onset of $\mathrm{AE}$ than in stable disease. Periostin immunohistochemical staining of lung pathological specimens showed that fibrotic regions with periostin-positive cells were larger in autopsied specimens in patients with AE than in SLB specimens collected from patients with stable disease.

$\alpha$-SMA staining was frequently positive in areas that stained positive with periostin. Therefore, localization of periostin was similar to that in $\alpha$-SMA-positive cells: myofibroblasts were stained in both cases. M-PN level at the onset of AE-FIP was weakly correlated with fibrosis score and definite UIP pattern. Thus, fibrosis activity at the onset of AE might be associated with serum M-PN.

Therefore, we focused on serial change in serum $(\Delta M$ $\mathrm{PN})$ levels of patients with AE-FIP. AE-FIP patients with a $\triangle \mathrm{M}-\mathrm{PN}$ level greater than $-2.7 \mathrm{ng} / \mathrm{mL}$ had worse outcomes, which might predict 3-month survival. However, we could not assess change in serum M-PN in patients who died within 7 days, so the possibility of bias in the results is a concern.

In AE-IPF, periostin regulates cells as a matricellular protein and activates myofibroblasts during abnormal repair of disorders in alveolar type II cells/vascular endothelial cells, through inflammation/coagulation disorder. Ashley et al. (32) suggested that periostin regulates fibrocyte function, thereby promoting myofibroblast differentiation and lung fibrosis. Thus, M-PN is likely involved in AEIPF. Serum periostin level at the onset of $\mathrm{AE}$ is positively associated with promotion of the abnormal repair process, and M-PN may thus be a prognostic factor in AE-FIP.

\section{Limitations}

This study has several limitations. First, it was a singlecenter study with a small sample size. Therefore, largescale studies are needed in order to confirm our results. Second, we could not measure serum M-PN before the onset of AE-FIP, i.e., during stable FIP. Thus, we could not directly compare AE-FIP and stable FIP in the same patients. Third, we could not analyze lung tissue obtained from surviving FIP-AE patients by surgical lung biopsy in this study. In addition, we could not evaluate histological staining of periostin because we did not perform lung biopsies in all IPF patients before onset of AE-FIP. We expect to investigate this issue in a future study. In immunohistochemical analysis, postmortem changes may have influenced the results. However, the widespread periostin protein expression in autopsied lung tissues of IPF-AE patients suggests that serum periostin level may be a biomarker for IPF-AE.

Finally, because we could not assess change in serum $\mathrm{M}-\mathrm{PN}$ in patients who died within 7 days, there is a possibility of bias in the results.

\section{Conclusions}

In conclusion, serum M-PN level was significantly higher in patients with AE-FIP than in healthy controls. A decline in serum M-PN level during the period from the onset of $\mathrm{AE}$ to day 7 was a predictor of 3 -month survival. Although the precise role of M-PN level in AE-FIP is unknown, M-PN level during AE-FIP may be a promising biomarker of 3-month survival after AE-FIP.

\section{Acknowledgments}

Junya Ono (SHINO-TEST Corporation, Kanagawa, Japan) 
measured serum monomeric and total periostin levels by using an enzyme-linked immunosorbent assay.

Funding: This research was partially supported by a grant from the Ministry of Health, Labour and Welfare of Japan, awarded to the Study Group on Diffuse Pulmonary Disorders.

\section{Footnote}

Reporting Checklist: The authors have completed the STROBE reporting checklist Available at http://dx.doi. org/10.21037/atm-21-414

Data Sharing Statement: available at http://dx.doi. org/10.21037/atm-21-414

Peer Review File: Available at http://dx.doi.org/10.21037/ atm-21-414

Conflicts of Interest: All authors have completed the ICMJE uniform disclosure form (available at http://dx.doi. org/10.21037/atm-21-414). The authors have no conflicts of interest to declare.

Ethical Statement: The authors are accountable for all aspects of the work in ensuring that questions related to the accuracy or integrity of any part of the work are appropriately investigated and resolved. The study was conducted in accordance with the Declaration of Helsinki (as revised in 2013). This study was approved by the Institutional Review Board of Toho University Omori Medical Center (project approval no.: 27-129; approval date: September 17, 2015). All patients or their families provided written informed consent, and medical records were reviewed with the approval of the Institutional Review Board.

Open Access Statement: This is an Open Access article distributed in accordance with the Creative Commons AttributionNonCommercial-NoDerivs 4.0 International License (CC BY-NC-ND 4.0), which permits the non-commercial replication and distribution of the article with the strict proviso that no changes or edits are made and the original work is properly cited (including links to both the formal publication through the relevant DOI and the license). See: https://creativecommons.org/licenses/by-nc-nd/4.0/.

\section{References}

1. Strieter RM, Mehrad B. New mechanisms of pulmonary fibrosis. Chest 2009;136:1364-70.

2. Izuhara K, Conway SJ, Moore BB, et al. Roles of Periostin in Respiratory Disorders. Am J Respir Crit Care Med 2016;193:949-56.

3. Okamoto M, Hoshino T, Kitasato Y, et al. Periostin, a matrix protein, is a novel biomarker for idiopathic interstitial pneumonias. Eur Respir J 2011;37:1119-27.

4. Uchida M, Shiraishi H, Ohta S, et al. Periostin, a matricellular protein, plays a role in the induction of chemokines in pulmonary fibrosis. Am J Respir Cell Mol Biol 2012;46:677-86.

5. Chandriani S, DePianto DJ, N'Diaye EN, et al. Endogenously expressed IL-13R $\alpha 2$ attenuates IL-13-mediated responses but does not activate signaling in human lung fibroblasts. J Immunol 2014;193:111-9.

6. Leppäranta O, Sens C, Salmenkivi K, et al. Regulation of TGF- $\beta$ storage and activation in the human idiopathic pulmonary fibrosis lung. Cell Tissue Res 2012;348:491-503.

7. Naik PK, Bozyk PD, Bentley JK, et al. Periostin promotes fibrosis and predicts progression in patients with idiopathic pulmonary fibrosis. Am J Physiol Lung Cell Mol Physiol 2012;303:L1046-56.

8. Kudo A. Periostin in fibrillogenesis for tissue regeneration: periostin actions inside and outside the cell. Cell Mol Life Sci 2011;68:3201-7.

9. O'Dwyer DN, Moore BB. The role of periostin in lung fibrosis and airway remodeling. Cell Mol Life Sci 2017;74:4305-14.

10. Tajiri M, Okamoto M, Fujimoto K, et al. Serum level of periostin can predict long-term outcome of idiopathic pulmonary fibrosis. Respir Investig 2015;53:73-81.

11. Izuhara K, Arima K, Ohta S, et al. Periostin in allergic inflammation. Allergol Int 2014;63:143-51.

12. Oka T, Xu J, Kaiser RA, et al. Genetic manipulation of periostin expression reveals a role in cardiac hypertrophy and ventricular remodeling. Circ Res 2007;101:313-21.

13. Ohta S, Shibata R, Nakao Y, et al. The usefulness of combined measurements of squamous cell carcinoma antigens 1 and 2 in diagnosing atopic dermatitis. Ann Clin Biochem 2012;49:277-84.

14. Ohta S, Okamoto M, Fujimoto K, et al. The usefulness of monomeric periostin as a biomarker for idiopathic pulmonary fibrosis. PLoS One 2017;12:e0174547.

15. Travis WD, Costabel U, Hansell DM, et al. An official American Thoracic Society/European Respiratory Society 
statement: Update of the international multidisciplinary classification of the idiopathic interstitial pneumonias. Am J Respir Crit Care Med 2013;188:733-48.

16. Ryerson CJ, Vittinghoff E, Ley B, et al. Predicting survival across chronic interstitial lung disease: the ILD-GAP model. Chest 2014;145:723-8.

17. Collard HR, Moore BB, Flaherty KR, et al. Acute exacerbations of idiopathic pulmonary fibrosis. Am J Respir Crit Care Med 2007;176:636-43.

18. Collard HR, Ryerson CJ, Corte TJ, et al. Acute Exacerbation of Idiopathic Pulmonary Fibrosis. An International Working Group Report. Am J Respir Crit Care Med 2016;194:265-75.

19. Kazerooni EA, Martinez FJ, Flint A, et al. Thin-section CT obtained at $10-\mathrm{mm}$ increments versus limited threelevel thin-section CT for idiopathic pulmonary fibrosis: correlation with pathologic scoring. AJR Am J Roentgenol 1997;169:977-83.

20. Akira M, Kozuka T, Yamamoto S, et al. Computed tomography findings in acute exacerbation of idiopathic pulmonary fibrosis. Am J Respir Crit Care Med 2008;178:372-8.

21. Kondoh Y, Taniguchi H, Kawabata Y, et al. Acute exacerbation in idiopathic pulmonary fibrosis. Analysis of clinical and pathologic findings in three cases. Chest 1993;103:1808-12.

22. Song JW, Hong SB, Lim CM, et al. Acute exacerbation of idiopathic pulmonary fibrosis: incidence, risk factors and outcome. Eur Respir J 2011;37:356-63.

23. Kondoh Y, Taniguchi H, Katsuta T, et al. Risk factors of acute exacerbation of idiopathic pulmonary fibrosis. Sarcoidosis Vasc Diffuse Lung Dis 2010;27:103-10.

Cite this article as: Shimizu H, Sakamoto S, Okamoto M, Isshiki T, Ono J, Shimizu S, Hoshino T, Izuhara K, Homma S. Association of serum monomeric periostin level with outcomes of acute exacerbation of idiopathic pulmonary fibrosis and fibrosing nonspecific interstitial pneumonia. Ann Transl Med 2021;9(9):739. doi: 10.21037/atm-21-414
24. Ryerson CJ, Cottin V, Brown KK, et al. Acute exacerbation of idiopathic pulmonary fibrosis: shifting the paradigm. Eur Respir J 2015;46:512-20.

25. Luppi F, Cerri S, Taddei S, et al. Acute exacerbation of idiopathic pulmonary fibrosis: a clinical review. Intern Emerg Med 2015;10:401-11.

26. Molyneaux PL, Cox MJ, Wells AU, et al. Changes in the respiratory microbiome during acute exacerbations of idiopathic pulmonary fibrosis. Respir Res 2017;18:29.

27. Kurosu K, Takiguchi Y, Okada O, et al. Identification of annexin 1 as a novel autoantigen in acute exacerbation of idiopathic pulmonary fibrosis. J Immunol 2008;181:756-67.

28. Kakugawa T, Yokota S, Ishimatsu Y, et al. Serum heat shock protein 47 levels are elevated in acute exacerbation of idiopathic pulmonary fibrosis. Cell Stress Chaperones 2013;18:581-90.

29. Tajima S, Oshikawa K, Tominaga S, et al. The increase in serum soluble ST2 protein upon acute exacerbation of idiopathic pulmonary fibrosis. Chest 2003;124:1206-14.

30. King TE Jr, Schwarz MI, Brown K, et al. Idiopathic pulmonary fibrosis: relationship between histopathologic features and mortality. Am J Respir Crit Care Med 2001;164:1025-32.

31. Nicholson AG, Fulford LG, Colby TV, et al. The relationship between individual histologic features and disease progression in idiopathic pulmonary fibrosis. Am J Respir Crit Care Med 2002;166:173-7.

32. Ashley SL, Wilke CA, Kim KK, et al. Periostin regulates fibrocyte function to promote myofibroblast differentiation and lung fibrosis. Mucosal Immunol 2017;10:341-51. 